\title{
Pulmonary function testing in spinal cord injury: correlation with vital capacity
}

\author{
EJ Roth, SB Nussbaum, M Berkowitz, S Primack, J Oken, S Powley and A Lu \\ Department of Physical Medicine and Rehabilitation, Northwestern University Medical School, Rehabilitation \\ Institute of Chicago, 345 East Superior Street, Chicago, Illinois 60611, USA
}

\begin{abstract}
Spinal cord injury (SCI) causes restrictive ventilatory changes, with reductions in vital capacity, functional residual capacity, and expiratory reserve volume. Vital capacity (VC) often is used as an indicator of overall pulmonary function in these patients. In an effort to determine the extent to which VC correlates with other pulmonary function tests, 52 patients with recent acute traumatic SCI underwent complete pulmonary function testing. Statistical relationships were determined between VC and nine other tests. VC was found to be significantly correlated with forced expiratory volume in $1 \mathrm{~s}$, inspiratory capacity, expiratory reserve volume, functional residual capacity, residual volume (RV), total lung capacity (TLC), and RV/TLC ratio, but not with maximum positive expiratory pressure nor with maximum negative inspiratory pressure. The excellent correlations between vital capacity and nearly all of the other pulmonary function tests support the use of $\mathrm{VC}$ as a single global measure of overall ventilatory status in SCI patients.
\end{abstract}

Keywords: spinal cord injury; pulmonary function testing; vital capacity

\section{Introduction}

Pulmonary function testing of patients with acute traumatic cervical or high thoracic spinal cord injury (SCI) reveals changes indicative of restrictive ventilatory dysfunction. In general, vital capacity is reduced by $30-50 \%$, functional residual capacity by approximately $25 \%$, and expiratory reserve volume by as much as $75 \% .{ }^{1-13}$ These findings reflect the loss of abdominal and chest wall muscle strength and control that results from SCI. ${ }^{7-9,14-16}$ Some consequences of these changes include rapid, shallow respirations, ${ }^{11}$ decreased ability to cough, and altered clearance of secretions. . $^{9,10,12,14-16}$ As a result, pneumonia, atelectasis, and other respiratory complications are common causes of morbidity and mortality in SCI patients. ${ }^{12,13,17-23}$

The frequent association between pulmonary complications and SCI suggests that periodic and frequent measurements of ventilatory status might be a useful component of SCI patient care. Bluechardt et $a l^{24}$ found that pulmonary function test (PFT) results during the acute phase after SCI are poor predictors of pulmonary function performance later, and that the time course of recovery is variable. Other author ${ }^{25}$ have confirmed that the changes in PFT results over time are inconsistent. These findings suggest that serial testing might be useful to assess status and progress over time.

Information is obtained from pulmonary function

This work was presented in part at the 53rd Annual Assembly of the American Academy of Physical Medicine and Rehabilitation, Washington DC, October 30, 1991 studies about the mechanical function of the respiratory system and its ability to increase workload in response to stress. While complete spirometric and volumetric assessments can be used to quantify and document ventilatory status, full pulmonary function testing often is unavailable, unfeasible, and expensive. Clearly, a simple and convenient method to measure and monitor ventilatory changes would facilitate the care of patients with SCI.

Vital capacity (VC), defined as the maximal volume of air that can be exhaled from the lungs following a maximal inspiration, ${ }^{26}$ has been used as a global measure of overall pulmonary function in a variety of settings. VC can also be used as a gross indicator of ventilatory reserve ${ }^{26,27}$ and of ability to breathe deeply and cough. ${ }^{26-28}$ These common applications of VC suggest that this test might be of value in assessing and monitoring the ventilatory status of SCI patients. The purpose of the present investigation was to determine the extent to which vital capacity correlated with other pulmonary function tests in SCI patients in order to assess the usefulness of $\mathrm{VC}$ as a global indicator of ventilatory status.

\section{Methods}

Patients

The sample consisted of 52 patients with recent acute traumatic spinal cord injury. All subjects had motor complete myelopathy of 6 months' duration or less, with injury levels ranging between the fourth cervical and sixth thoracic spinal cord segments. All patients 
had full spontaneous ventilation. None of the subjects had unilateral diaphragm paralysis. Patients with open tracheostomy were excluded from the study. Associated chest injuries sustained at the time of SCI and pneumonias suffered after SCI were completely resolved prior to the time at testing. All patients gave informed consent for participation in the study.

\section{Procedures}

Data that were recorded on each patient included age, gender, history of smoking, etiology and level of injury (as defined by the American Spinal Injury Association criteria), associated chest injuries, history of pneumonia, history of tracheostomy, and the use of spinal orthosis.

Each patient underwent complete pulmonary function testing in the sitting position, using the Cybermedics Pulmonary Function Testing Machine (Cybermedics Inc, Louisville, Colorado, USA). Tests included measurements of forced vital capacity, and forced expiratory volume in $1 \mathrm{~s}$, inspiratory capacity, expiratory reserve volume, functional residual capacity, residual volume (RV), total lung capacity (TLC), and RV/TLC. A Boehringer Model 4101 (Boehringer Laboratories Inc, Wynnewood, PA, USA) hand-held manometer was used to measure maximum positive expiratory pressure and negative inspiratory pressure.

\section{Data analysis}

Simple linear regression analysis was performed to determine relationships between vital capacity and each of the nine other pulmonary function tests. Criterion for statistical significance was considered to be $P<0.05$.

\section{Results}

The sample of 52 patients had a mean ( \pm s.d.) age of $29.9 \pm 11.6$ years (range 15-57 years). There were $41(79 \%)$ males. Twenty-seven patients $(52 \%)$ gave a history of smoking and three $(6 \%)$ had a history of pneumonia. Thirty (58\%) had used a tracheostomy, and $13(25 \%)$ had used a spinal orthosis. Eleven subjects $(21 \%)$ sustained associated chest injuries at the time of SCI, all of which were completely resolved at the time of participation in the study.

Etiology of injury was road and traffic accident in 27 $(52 \%)$, fall in $12(23 \%)$, sports and diving in six $(12 \%)$, gunshot wound in five $(10 \%)$, and other in two $(3 \%)$. Level of injury was C4 in seven (14\%), C5 in eight $(15 \%)$, C6 in $18(35 \%)$, C7 in $10(19 \%)$, C 8 in one $(2 \%)$, and upper thoracic in eight $(15 \%)$.

Mean ( \pm s.d.) values for the pulmonary function tests were: vital capacity $(\mathrm{VC})=1.9 \pm 0.7 \mathrm{l}$; forced expiratory volume in $1 \mathrm{~s}\left(\mathrm{FEV}_{1}\right)=1.7 \pm 0.6 \mathrm{l}$; inspiratory capacity $(\mathrm{IC})=1.6 \pm 0.6 \mathrm{l}$; expiratory reserve volume $(E R V)=0.3 \pm 0.3 \mathrm{l}$; functional residual capacity $(\mathrm{FRC})=2.6 \pm 0.8 \mathrm{l}$; residual volume $(\mathrm{RV})=$ $2.3 \pm 0.7 \mathrm{l} ;$ total lung capacity $(\mathrm{TLC})=4.2 \pm 1.1 \mathrm{l}$; $\mathrm{RV} / \mathrm{TLC}=54.1 \pm 12.0$, maximum positive expiratory pressure $=+62.3 \pm 29.4 \mathrm{cmH}_{2} \mathrm{O}$; and maximum negative inspiratory pressure $=-49.4 \pm 22.0 \mathrm{cmH}_{2} \mathrm{O}$.

Results of the linear regression analysis to determine relationships between vital capacity and each of the other pulmonary function tests are shown in Table 1 and Figures 1-7. These results indicate that VC correlated significantly with $\mathrm{FEV}_{1}$, IC, ERV, FRC, RV, TLC, and RV/TLC, but not with maximum

Table 1 Correlations between vital capacity and each of the other pulmonary function tests

\begin{tabular}{lcc}
\hline PFT & $R^{2}$ & $p$ \\
\hline FEV $_{1}, 1$ & 0.882 & $<0.001$ \\
IC, l & 0.814 & $<0.001$ \\
ERV, l & 0.356 & $<0.001$ \\
FRC, l & 0.204 & 0.002 \\
RV, l & 0.138 & 0.015 \\
TLC, 1 & 0.594 & $<0.001$ \\
RV/TLC & 0.222 & 0.002 \\
PEP, $\mathrm{cmH}_{2} \mathrm{O}$ & 0.022 & NS \\
NIP, $\mathrm{cmH}_{2} \mathrm{O}$ & 0.043 & NS \\
\hline
\end{tabular}

$\mathrm{PFT}=$ pulmonary function test $; \mathrm{FEV}_{1}=$ forced expiratory volume in $1 \mathrm{~s}$; IC = inspiratory capacity; ERV = expiratory reserve volume; $\mathrm{FRC}=$ functional residual capacity; $\mathrm{RV}=$ residual volume; $\mathrm{TLC}=$ total lung capacity; $\mathrm{RV} / \mathrm{TLC}=$ residual volume, '́total lung capacity ratio; $\mathrm{PEP}=$ maximum positive expiratory pressure; NIP = maximum negative inspiratory pressure; NS = not significant

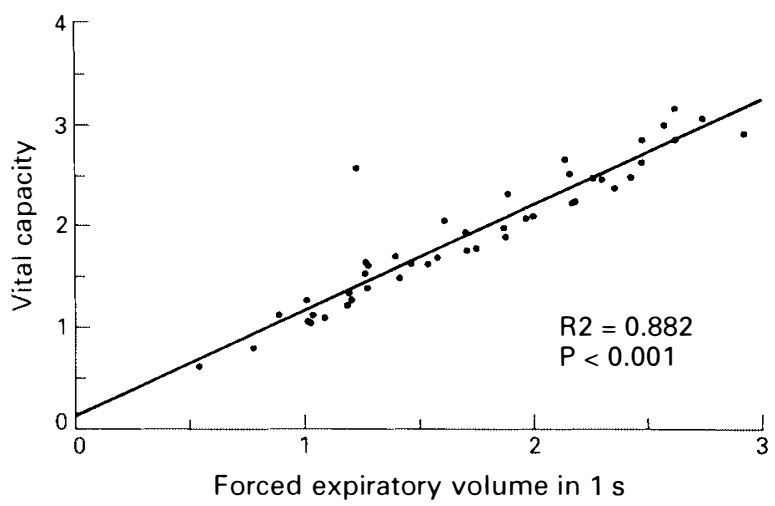

Figure 1 Forced expiratory volume in $1 \mathrm{~s} v s$ vital capacity

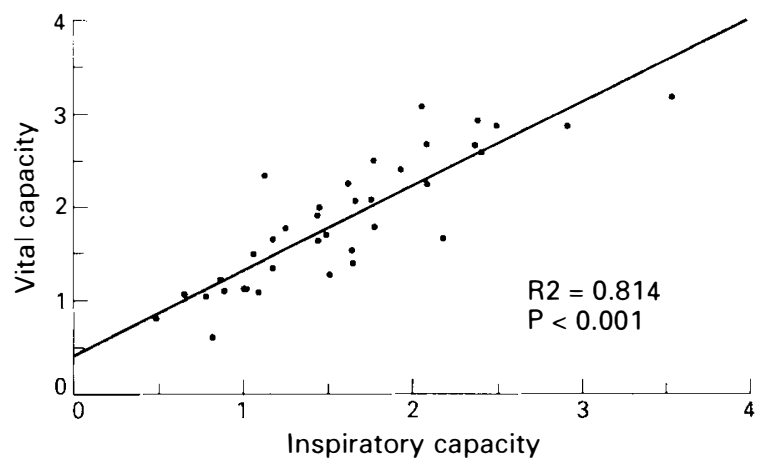

Figure 2 Inspiratory capacity $v s$ vital capacity 
456

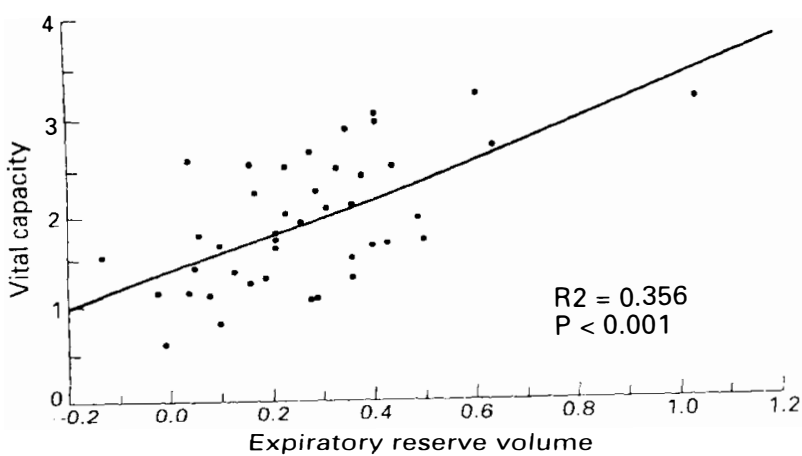

Figure 3 Expiratory reserve volume vs vital capacity

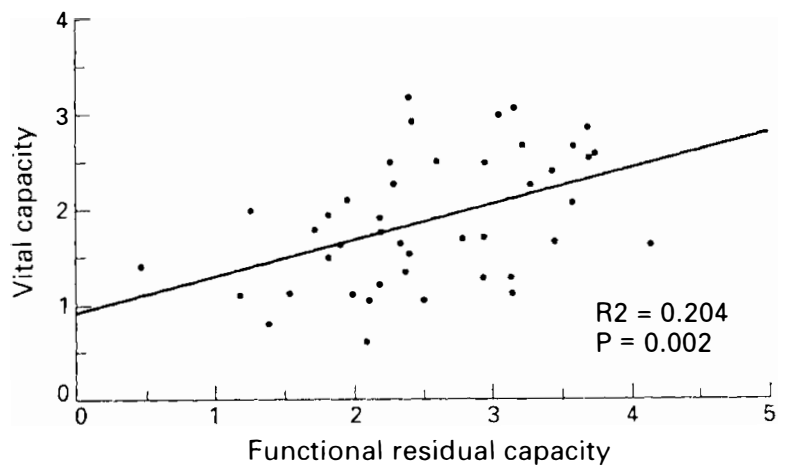

Figure 4 Functional residual capacity vs vital capacity

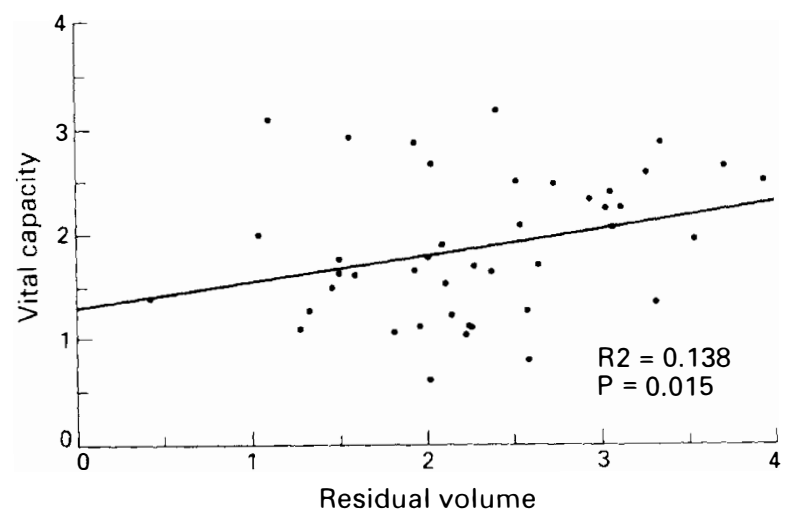

Figure 5 Residual volume vs vital capacity

positive expiratory pressure, nor with maximum negative inspiratory pressure.

\section{Discussion}

Respiratory insufficiency and pulmonary complications are major contributing factors to morbidity and mortality in patients with cervical or high thoracic spinal cord injuries. ${ }^{12,13,17-23}$ For this reason, assessment and serial

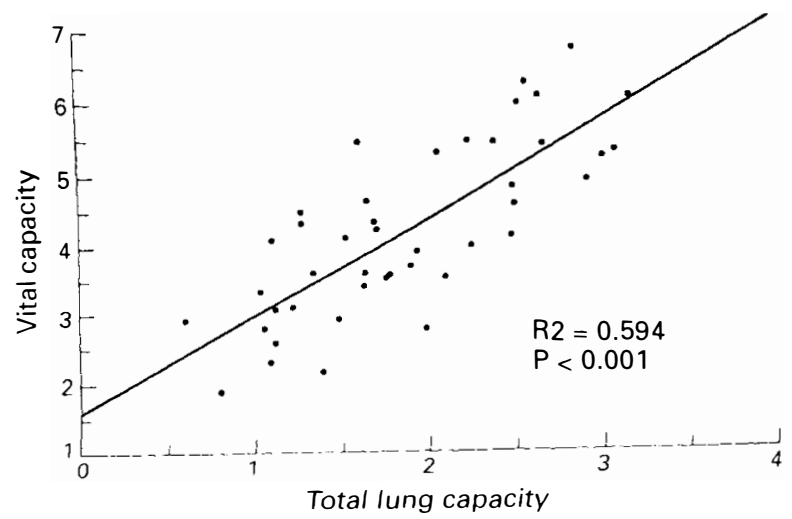

Figure 6 Total lung capacity vs vital capacity

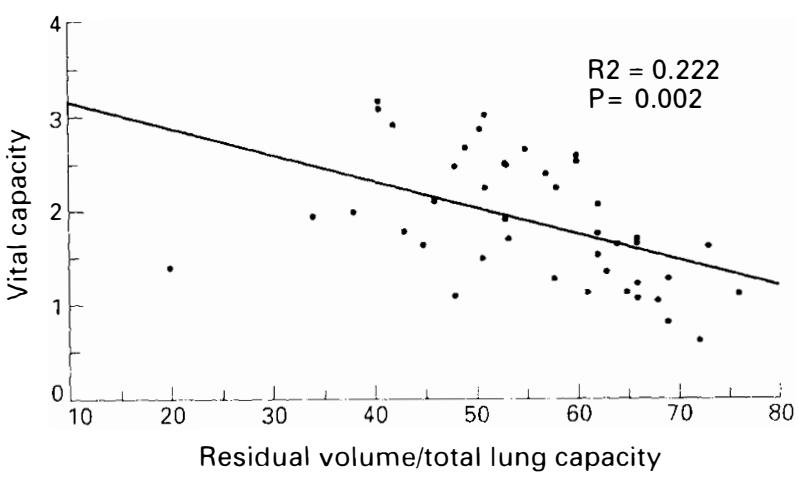

Figure 7 Residual volume/total lung capacity vs vital capacity

monitoring of ventilatory status using pulmonary function testing are useful and effective components of the comprehensive care of these patients. Because vital capacity (VC) measurement is inexpensive and easy to perform at the bedside ${ }^{26}$ use of this test alone might be more practical than full pulmonary function testing in some settings. While VC measurements are commonly incorporated into clinical practice, scientific justification for their use has been lacking.

Vital capacity is defined as the maximum amount of air that a person can exhale following a maximum inspiration. ${ }^{26}$ This test can be used to determine the patient's ability to breathe deeply, to develop an effective cough, and to clear secretions. ${ }^{26-28}$ Vital capacity measurement also can indicate limitations in the capacity of the body to maintain a disease-free pulmonary system. ${ }^{26}$ Historically, VC has been used as a bedside measure of ventilatory reserve in both critically ill and chronic non-SCI patients. ${ }^{26}$ This evaluation can be particularly useful in determining a patient's ability to maintain adequate gas exchange without undue work of breathing. ${ }^{26}$

The results of the present investigation demonstrate that vital capacity is correlated with most of the other pulmonary function tests, suggesting that vital capacity 
may be a useful indicator of overall ventilatory function. Unlike other, more complicated, testing methods, VC can be measured using a convenient, easily transportable, hand-held device. Potential beneficial effects of using vital capacity measurements in SCI patients include earlier detection of respiratory compromise and improved monitoring of clinical progress. Early detection of ventilatory dysfunction may prevent rapid and serious deterioration of pulmonary status. Use of this less expensive alternative technique can be especially useful in the present era of cost containment. It should be noted, however, that VC serves only as a gross measure of overall pulmonary function, rather than as a substitute for full spirometric and volumetric testing.

Vital capacity was found to have no correlation with maximum negative inspiratory pressure (NIP) or positive expiratory pressure (PEP). This finding may reflect the fact that NIP and PEP are pressure measurements while vital capacity and all other pulmonary function tests are volumetric in nature. While it is noted that VC alone may be a singularly practical and useful test, NIP and PEP measurements provide additional information that could be valuable in the clinical setting.

Only one of the relationships evaluated in the present investigation has been studied in the past. Results of the current study confirm those of prior investigations ${ }^{11,24}$ that there is a strong and significant correlation between $\mathrm{FEV}_{1}$ and VC in SCI patients. The findings that $\mathrm{VC}$ measurements are also related to other PFT results are new.

It was important to exclude patients with open tracheostomies from the study in order to eliminate the potential for erroneous pulmonary function test results. Patients who suffered chest injuries or pneumonias were included because they represented a sizable proportion of individuals with SCI, their injuries or illnesses were resolved at the time of testing, and it was felt that their pulmonary function test results therefore would not alter the findings of the study.

Pulmonary function tests generally are used to evaluate ventilatory status in SCI patients, and can be used to indicate risk of clinical pulmonary complications. The high degree of correlation between vital capacity and most of the other tests supports the common clinical use of $\mathrm{VC}$ for this purpose.

\section{Acknowledgements}

This research was supported by the US Department of Education National Institute on Disability and Rehabilitation Research, Washington DC, through the Rehabilitation Research and Training Center on Prevention and Treatment of Secondary Complications of Spinal Cord Injury (Grant H133B80007), the Dr Scholl Foundation, Chicago, IL, and the Rehabilitation Institute of Chicago. The authors are grateful to Jeffrey S Roth, ASA for statistical consultation.

\section{References}

1 Bergofsky EH. Quantitation of the function of the respiratory muscles in normal individuals and quadriplegic patients. Arch Phys Med Rehabil 1964; 45: 575-580.

2 Fugl-Meyer AR. Effects of respiratory muscle paralysis in tetraplegic and paraplegic patients. Scand J Rehabil Med 1971; 3: $141-150$.

3 Fugl-Meyer A. Ventilatory function in tetraplegic patients. Scand J Rehabil Med 1971; 3: 151-160.

4 Haas $\mathrm{F}$ et al. Temporal pulmonary function changes in cervical cord injury. Arch Phys Med Rehabil 1985; 66: 139-143.

5 Ledsome JR, Sharp JM. Pulmonary function in acute cervical cord injury. Am Rev Respir Dis 1981; 124: 41-44.

6 Ohry A, Molhom M, Rozin R. Alterations of pulmonary function in spinal cord injured patients. Paraplegia 1975; 13: 101-108.

7 Forner JV. Lung volumes and mechanics of breathing in tetraplegics. Paraplegia 1980; 18: 258-266.

8 Stone DJ, Kelz $\mathrm{H}$. The effect of respiratory muscle dysfunction on pulmonary function: Studies in patients with spinal cord injuries. Am Rev Respir Dis 1963; 88: 621-629.

9 DeTroyer A, Helporn A. Respiratory mechanics in quadriplegia: The respiratory function of the intercostal muscles. Am Rev Respir Dis 1980; 122: 591-600.

10 Loveridge B, Sanii R, Dubo HI. Breathing pattern adjustments during the first year following cervical spinal cord injury. Paraplegia 1992; 30: 479-488.

11 Loveridge F, Dubo HI. Breathing pattern in chronic quadriplegia. Arch Phys Med Rehabil 1990; 71: 495-499.

12 McKinley AC, Auchincloss JH Jr, Gilbert R, Nicholas JJ. Pulmonary function, ventilatory control, and respiratory complications in quadriplegic subjects. Am Rev Respir Dis 1969; 100: $526-532$

13 McMichan JC, Michel L, Westbrook PR. Pulmonary dysfunction following traumatic quadriplegia: Recognition, prevention, and treatment. JAMA 1980; 243: 528-531.

14 Saltzstein R, Melvin J. Ventilatory compromise in spinal cord injury-A review. J Am Paraplegia Soc 1987; 10: 6-9.

15 Mortola JP, Sant'Ambroglio G. Motion of the rib cage and abdomen in tetraplegia patients. Clin Sci 1978; 54: 25-32.

16 Siebens AA, Kirby NA, Poulos DA. Cough following transection of spinal cord at C6. Arch Phys Med Rehabil 1964; 45: $1-8$.

17 DeVivo MJ et al. Cause of death for patients with spinal cord injuries. Arch Intern Med 1989; 149: 1761-1766.

18 Geisler WO, Jousse AT, Wynne-Jones M. Survival in traumatic transverse myelitis. Paraplegia 1977; 14: 262-275.

19 Minaire $\mathrm{P}$ et al. Life expectancy following spinal cord injury: A ten year survey in the Rhome-Alpes Region, France, 1969-1980. Paraplegia 1983; 21: 11-15.

20 Ravichandran G, Silver JR. Survival following traumatic tetraplegia. Paraplegia 1982; 20: 264-269.

21 Fishburn MJ, Marino RJ, Ditunno JF. Atelectasis and pneumonia in acute SCI. Arch Phys Med Rehabil 1990; 71 197-200.

22 Deverat $\mathrm{P}$ et al. Initial factors predicting survival in patients with SCI. J Neurol Neurosurg Psychiatry 1989; 52: 403-406.

23 Bellamy R, Pitts FW, Stauffer ES. Respiratory complications in traumatic quadriplegia: Analysis of 20 years' experience. J Neurosurg 1973; 39: 596-600.

24 Bluechardt MH, Wiens M, Thomas SG, Plyley MJ. Repeated measurements of pulmonary function following spinal cord injury. Paraplegia 1992; 30: 768-774.

25 Ashba $\mathrm{J}$ et al. Spirometry-acceptability and reproducibility in spinal cord injured subjects. J Am Paraplegia Soc 1993; 16: 197-203.

26 Shapiro BA, Harrison RA, Trout CA. Clinical Application of Respiratory Care, 2nd edn. Yearbook Medical Publishers: Chicago, 1979, pp 98-114.

27 Bendixen HH. Respiratory Care. CV Mosby, St Louis, 1965, p 51.

28 Petty TL. Intensive and Rehabilitative Respiratory Care. Lea and Febiger: Philadelphia, 1971, pp 354-355. 